\title{
Um estudo das deliberações da Câmara Setorial do Açúcar e do Álcool, usando análise de correspondência
}

\author{
Carlos Alberto Gonçalves Júnior ${ }^{1}$ \\ Yony Brugnolo Alves ${ }^{2}$ \\ Pery Francisco Assis Shikida ${ }^{3}$ \\ Jefferson Andronio Ramundo Staduto ${ }^{4}$ \\ Weimar Freire da Rocha Júnior ${ }^{5}$
}

Resumo: Este artigo trata das deliberações da Câmara Setorial da Cadeia Produtiva do Açúcar e do Álcool do Ministério da Agricultura, Pecuária e Abastecimento (Mapa). As principais ações da Câmara em estudo ocorreram no sentido de solicitar alterações nos ambientes tecnológico, institucional e organizacional, buscando a diminuição dos custos de transação, principalmente em relação ao nível informacional dos membros. Por meio da análise multivariada, percebe-se que a maioria das reuniões da Câmara trata de solicitações quanto a alterações no ambiente institucional, principalmente no que diz respeito aos aspectos tributários.

${ }^{1}$ Economista. Mestre em Desenvolvimento Regional e Agronegócio na Unioeste (Universidade Estadual do Oeste do Paraná). E-mail: carlosalberto@faculdadesmaringa.br

${ }^{2}$ Economista. Mestranda em Desenvolvimento Regional e Agronegócio na Unioeste (Universidade Estadual do Oeste do Paraná). E-mail: yony@codem.org.br

${ }^{3}$ Professor Associado do Curso de Economia e do Mestrado em Desenvolvimento Regional e Agronegócio da Unioeste. Bolsista de Produtividade em Pesquisa do CNPq e pesquisador do Gepec. E-mail: pfashiki@unioeste.br

${ }^{4}$ Professor Adjunto do Curso de Economia e do Mestrado em Desenvolvimento Regional e Agronegócio da Unioeste. Bolsista de Produtividade em Pesquisa do CNPq e pesquisador do Gepec. E-mail: staduto@yahoo.com.br

5 Professor Adjunto do Curso de Economia e do Mestrado em Desenvolvimento Regional e Agronegócio da Unioeste. Bolsista de Produtividade em Pesquisa da Fundação Araucária e pesquisador do Gepec. E-mail: wrocha@unioeste.br. Os autores são gratos aos pareceristas desta Revista pelas profícuas sugestões e comentários. 
Palavras-chaves: Câmara Setorial, setor sucroalcooleiro, Nova Economia Institucional, análise de correspondência.

\title{
Classificação JEL: Q1, L52.
}

\begin{abstract}
This article discusses the deliberations of the Sectional Council of Productive Chain of Sugar and Alcohol of Agricultural, Live-stocking farming and Supply Department. The main actions of the Council is study occurred in the sense of requesting alters in the technologic, institutional and organizational environment aiming a fall of dealing costs, mainly in relation to the informational level of the members. Through the multivariate analysis, it is noticed that most of the meetings of the Council deals with the requests in relation to the alterations in the institutional environment, mainly to what relates to the taxes aspects.
\end{abstract}

Key-words: Sectional Council, sugar and alcohol sector, New Institutional Economy, correspondence analysis.

JEL Classification: Q1, L52.

\section{Introdução}

O surgimento das Câmaras Setoriais não é um acontecimento isolado, ele faz parte de um processo histórico iniciado pós-década de 80, com uma significativa mudança no papel que o Estado brasileiro desempenhava desde a Primeira República. Assim, para tratar das Câmaras Setoriais, primeiramente faz-se necessário um breve levantamento histórico a respeito do papel do Estado no processo de desenvolvimento econômico do País.

De acordo com Gremaud et al. (2002), durante o período correspondente à Primeira República, o Estado não tinha um papel muito ativo, apesar das políticas de controle de preço e produção de café. Muitos serviços públicos eram oferecidos por empresas privadas. Porém, após a crise de 1929, a iniciativa privada perdeu seu poder de autofinanciamento, e a necessidade de acelerar o processo de industrialização fez com que o Estado assumisse um papel mais dinâmico e passasse a ser o condutor, regulador, produtor e financiador do processo de industrialização brasileira. 
Esse papel centralizador que o Estado assumiu depois da crise de 1929 se intensificou nos governos militares, sendo que o Estado se tornou cada vez mais interventor no processo de desenvolvimento econômico do País, tal status quo manteve-se até a década de 80.

Para Baer (2002), a partir de meados da década de 70 o modelo "tripé" (Estado, Capital Nacional e Capital Internacional), iniciado em 1930, foi sendo gradualmente derrubado, à medida que o envolvimento do Estado na Economia se tornou uma força cada vez mais negativa. No período posterior a década de 80 , boa parte da institucionalidade montada desde os anos 30 se desmoronou.

Segundo Gremaud et al. (2002), apesar de ainda ter alguns instrumentos condutores do desenvolvimento econômico em alguns setores, o Estado não se utiliza desses instrumentos com a mesma intensidade que em períodos anteriores.

As reformas no papel do Estado, constatadas nos últimos anos, se deram devido às crises econômicas significativas, cuja raiz, para muitos, está no próprio Estado, no seu descontrole fiscal e na sua ineficiência. Por isso, tentativas de racionalização do controle financeiro e administrativo do poder público nacional, como a Lei de Responsabilidade Fiscal e a privatização de empresas públicas (Programa Nacional de Desestatização) procuram redefinir o papel do Estado na economia (BACHA, 2004).

Nesse contexto, surgem as Câmaras Setoriais, no qual o Estado abre espaço para a atuação do setor privado na condução das políticas setoriais, porém, continua participando nas decisões, dada a característica "tripartite" das Câmaras (Estado, Empresas, Trabalhadores).

O desempenho do agronegócio brasileiro sempre esteve ligado à ação do Estado, como financiador e condutor das políticas (BACHA, 2004). Porém, com a mudança na atuação do Estado, fez-se necessário, também, mudanças na organização do setor. A abundância de recursos naturais, clima favorável, evolução biotecnológica e da tecnologia mecânica, sempre foram fatores relevantes para o bom desempenho do agronegócio brasileiro. É preciso, contudo, considerar a evolução da tecnologia organizacional que disponibiliza informações de mercado para a tomada de decisão dos agricultores e harmoniza os interesses entre os diferentes elos da cadeia produtiva.

As Câmaras Setoriais do Agronegócio são o resultado da evolução tecnológica organizacional do setor, pois estabelecem ações prioritárias, 
discutem questões relativas ao suprimento de produtos ou insumos em quantidade e qualidade e estabelecem preços que remunerem todos os agentes, incentivando agricultores a permanecerem na atividade. Além dos interesses privados, interesses públicos também são abordados no âmbito das Câmaras, como a garantia de suprimentos dos bens e serviços e crescimento sustentado da cadeia, aumento da renda, do emprego e as externalidades da cadeia.

O agronegócio é de extrema importância para a economia brasileira. De acordo com dados do Ministério da Agricultura, Pecuária e Abastecimento - Mapa (2006), em sua Secretaria de Relações Internacionais do Agronegócio, no ano de 2005, o PIB do agronegócio representou $27,87 \%$ do PIB brasileiro, além de ser responsável por grande número de empregos no País. No mercado externo, em 2005, o agronegócio foi responsável por 36,9\% do total das exportações. Além disso, o Brasil é líder nas exportações de produtos como carnes bovina e de aves, café, soja, suco de laranja e açúcar.

De acordo com dados do Mapa (2006), somente o setor sucroalcooleiro movimenta cerca de US\$ 60 bilhões por ano, é formado por cerca de 320 usinas, 65 mil produtores independentes de cana-de-açúcar e 3 milhões de trabalhadores. O PIB do setor, em 2005, foi de aproximadamente R\$ 37,8 bilhões.

Neste contexto, o presente artigo tem como objetivo verificar as principais deliberações da Câmara Setorial da Cadeia Produtiva do Açúcar e do Álcool (também chamada amiúde de Câmara Setorial do Açúcar e do Álcool) no sentido de influenciar os ambientes institucional, tecnológico e organizacional nos quais está inserida. Esta análise é feita por meio das atas das reuniões desta Câmara, tendo como referencial teórico a Nova Economia Institucional (NEI). Complementarmente, utiliza-se a técnica estatística de análise de correspondência para aferição de resultados quantitativos.

Para atingir o objetivo, este artigo está dividido em sete seções. Além dessa introdução, na seção 2, ressaltam-se concisas notas sobre o setor sucroalcooleiro no Brasil. A seção 3 trata especificamente das Câmaras Setoriais no Brasil e da Câmara Setorial do Açúcar e do Álcool, enquanto, na seção 4, é feito um levantamento dos aspectos teóricos relacionados à NEI. Em seguida são abordados os aspectos metodológicos e na seção 6 são apresentados os resultados e as discussões derivadas da pesquisa quantitativa. Na seção 7, encontram-se as considerações finais deste trabalho. 


\section{O setor sucroalcooleiro brasileiro}

Conforme citado anteriormente, o desempenho do agronegócio brasileiro sempre esteve ligado à ação do Estado. Isso não foi diferente para o setor sucroalcooleiro, que segundo Shikida (1997), esteve historicamente sob o intervencionismo governamental. E, a partir da década de 1930, com a criação do Instituto do Açúcar e do Álcool (IAA), esse intervencionismo foi mais evidente e organizado, proporcionando ao setor uma série de arranjos institucionais que aliava os interesses do setor às estruturas de decisão do Estado. Em 1975 foi criado o Proálcool que, de acordo com Shikida (1997), passou por três fases, uma de expansão moderada, uma de expansão acelerada e a última de desaceleração e crise do Programa, evidenciando mais uma vez a intervenção estatal no setor. Outrossim, pari passu ao período de crise do Proálcool, e ressurgimento deste Programa dado mediante mormente nova elevação dos preços do petróleo e lançamento do veículo flex fuel, o setor passa a ter uma dinâmica própria, em ambiente desregulamentado (PAULILLO et al., 2007).

De acordo com Moraes (2000), os efeitos da liberalização no setor sucroalcooleiro foram sentidos tanto no ambiente institucional como no organizacional. No ambiente institucional, questões como a Portaria do Ministério da Fazenda n. 64, de março de 1996, tratou da liberação dos preços dos produtos do setor - os quais só foram liberados de fato em fevereiro de 1999.

Vale dizer, segundo Moraes (2000), que o ambiente organizacional é dividido entre público e privado. $\mathrm{O}$ ambiente organizacional público está relacionado a questões como a extinção do IAA, criação do Conselho Interministerial do Açúcar e do Álcool (Cima), criação da Agência Nacional do Petróleo (ANP) e abertura do mercado de combustíveis, além da criação da Associação dos Municípios Canavieiros do Estado de São Paulo (Amcesp) e da Câmara Paulista do Setor Sucroalcooleiro. E ao ambiente organizacional privado estão ligadas questões como a criação da União da Agroindústria Canavieira de São Paulo (Unica), fundação da Coligação das Entidades Produtoras de Açúcar e Álcool (Cepaal), fundação da Associação Paulista da Agroindústria Sucroalcooleira (Sucroalco), criação da Brasil Álcool S/A e a criação da Bolsa Brasileira de Álcool (BBA). 
De acordo com Vilela e Araújo (2006) e Paulillo et al. (2006), o setor sucroalcooleiro brasileiro é um dos poucos a apresentarem, na atualidade, grande expressividade social e econômica. Isto pode ser traduzido pela quantidade de empregos gerados pelo setor e principalmente pelo seu grande potencial de crescimento em face da possibilidade de um mercado internacional do álcool, tendo em vista os elevados preços do petróleo e principalmente as exigências ambientais traduzidas nas regulamentações do Protocolo de Kyoto. Conforme dados do Mapa (2006), em 2006, foram plantados mais de 7 milhões de hectares de cana-de-açúcar, $25 \%$ a mais do que no ano anterior, o que mostra as boas expectativas do setor diante do mercado.

\section{Breve histórico das câmaras setoriais}

As Câmaras Setoriais são resultado do processo histórico de mudança do papel do Estado no desenvolvimento econômico do País. Essa ação pode ser explicada com um foco corporativista, como abordado em Anderson (1999), Takagi (2004), e utilizando-se de uma abordagem combinada entre o corporativismo e a NEI, segundo Schmidtke et al. (2006). Porém, o presente artigo traz uma abordagem exclusivamente baseada na NEI para explicar o papel da Câmara Setorial do Açúcar e do Álcool do Ministério da Agricultura Pecuária e Abastecimento e sua importância para o setor.

As Câmaras Setoriais foram instituídas no ano de 1988, por meio do Decreto no 96.056 , no seu artigo sétimo. Essa foi a primeira legislação no Brasil sobre Câmaras Setoriais, e no ano seguinte, através da Resolução no 13 da Secretaria Especial de Desenvolvimento Industrial (SDI), as Câmaras Setoriais foram efetivamente criadas com o objetivo de "[...] elaborar diagnósticos de competitividade setorial, identificar as causas das distorções existentes e indicar as estratégias para seu equacionamento" (ANDERSON, 1999, p.2).

De acordo com Anderson (1999), os objetivos iniciais das Câmaras Setoriais sempre estiveram voltados para políticas industriais. Porém, devido ao contexto da década de 1980, de alta inflação, as Câmaras passaram a atuar também como locus de discussão da instabilidade monetária. 
Para Staduto et al. (2007), naquele momento, as Câmaras tinham um caráter bipartite, ou seja, eram formadas apenas pelos empresários e pelo governo e os trabalhadores ainda não tinham participação. Essa composição das Câmaras durou pouco tempo, visto que estas acabaram tornando-se um meio de pressão dos empresários sobre o Estado, e fracassaram, também, como mecanismo de controle da instabilidade monetária.

Em fevereiro de 1991, na saída do congelamento do Plano Collor II, as Câmaras Setoriais novamente foram propostas como mecanismo de controle inflacionário. Nessa fase, contudo, já incluíam a participação dos trabalhadores na sua composição, passando a assumir um caráter tripartite (empresários-governo-trabalhadores) (STADUTO et al., 2007).

Takagi (2004) ressalta que, após a abertura econômica, que levou a uma redução na participação do Estado no controle econômico, e o caráter tripartite assumido pelas Câmaras Setoriais, estas assumiram um papel maior, promovendo acordos e buscando caminhos para superar a crise do setor industrial.

Para Anderson (1999), as Câmaras Setoriais, a partir da sua institucionalização, foram definidas como um locus de organização e negociação entre governo, empresários e trabalhadores. Esse inédito caráter tripartite representou uma considerável evolução nas relações capital-trabalho, devido à inclusão dos trabalhadores na elaboração de políticas para o setor, independentemente dos resultados alcançados.

A utilização das Câmaras como locus de discussão envolve questões ideológicas como intervenção do Estado no mercado e relações capital-trabalho, além de relações econômicas, já que acordos firmados por algumas Câmaras afetaram outros setores da economia.

Após 1992, as Câmaras passaram a tratar mais das questões da indústria de forma setorial. No entanto, em 1995, de acordo com Takagi (2004), estas foram se esvaziando e deixando de ser um lugar de debates e formulação de políticas para a indústria, até serem desativadas.

Anderson (1999) deixa claro que, desde o início, as funções das Câmaras Setoriais não foram bem definidas, o que sempre deixou margem para a mudança de rumo de suas ações sempre que atendesse aos interesses majoritários.

Em 2003, com a recriação do Conselho Nacional de Política Agrícola (CNPA), as Câmaras Setoriais foram reinstaladas. De acordo com Vilela e Araújo (2006), no Ministério da Agricultura, Pecuária e Abastecimento 
- Um estudo das deliberações da Câmara Setorial do Açúcar

e do Álcool, usando análise de correspondência

existem cerca de 24 Câmaras Setoriais e 6 Temáticas, que funcionam como um elo entre o governo e a iniciativa privada e resultam num mecanismo transparente e democrático de participação da sociedade na formação das políticas públicas.

As Câmaras Setoriais estão relacionadas com o agrupamento de segmentos da cadeia produtiva e as Temáticas não têm relação direta com uma cadeia, mas sim com serviços ou temas ligados ao agronegócio. Ambas têm seus valores voltados para a equidade no tratamento entre os diferentes elos das cadeias produtivas, qualidade nos serviços, segurança alimentar e principalmente para a harmonização entre os setores e igualdade entre público e privado na sua co-gestão.

Para Vilela e Araújo (2006), as Câmaras são constituídas por entidades de caráter nacional que representam produtores, trabalhadores, consumidores, empresários, autoridades do setor privado, representantes de órgãos públicos e instituições bancárias.

O Quadro 1 sintetiza os principais decretos e resoluções referentes às Câmaras Setoriais desde a década de 1980, trazendo, também, a instalação e a criação da Câmara Setorial do Açúcar e do Álcool.

Quadro 1. Evolução Histórica da Regulamentação da Câmara

\begin{tabular}{|l|c|}
\hline Principais medidas institucionais & Objetivos \\
\hline $19 / 05 / 1988$ - Decreto no 96.056 & $\begin{array}{c}\text { Reorganizou o Conselho de Desenvolvimento } \\
\text { Industrial (CDI) e instituiu a Secretaria de } \\
\text { Desenvolvimento Industrial (SDI), ou seja, as } \\
\text { Câmaras Setoriais. }\end{array}$ \\
\hline $\begin{array}{l}\text { Criação das Câmaras Setoriais. } \\
\text { (não chegou a funcionar, } \\
\text { tratando-se de um esboço de lei). }\end{array}$ & $\begin{array}{c}\text { Dispõe sobre a estruturação do Conselho } \\
\text { Nacional de Agricultura. Previa a participação do } \\
\text { setor privado juntamente com o setor público na } \\
\text { formulação políticas agrícolas. }\end{array}$ \\
\hline $\begin{array}{l}\text { 17/01/1991 - Lei no } 8.171 \\
\text { Criação das Câmaras Setoriais no no } 13 \\
\text { Ministério da Agricultura }\end{array}$ & $\begin{array}{l}\text { Dispõe sobre a política agrícola. Criou o Conselho } \\
\text { Nacional de Política Agrícola (CNPA) constituído } \\
\text { por representantes do governo e da iniciativa } \\
\text { privada: CNA, da OCB, da Contag. O CNPA } \\
\text { contará com uma secretaria executiva e sua } \\
\text { estrutura funcional será integrada por Câmaras } \\
\text { Setoriais especializadas em produtos, insumos, } \\
\text { comercialização, armazenamento, transporte, } \\
\text { crédito, seguro e demais componentes da } \\
\text { atividade rural. }\end{array}$ \\
\hline
\end{tabular}


Quadro 1. Continuação

\begin{tabular}{|c|c|}
\hline Principais medidas institucionais & Objetivos \\
\hline 1993 - Desativação do CNPA & $\begin{array}{l}\text { Desativação do CNPA. Em função dos diversos } \\
\text { vetos sofridos pela Lei no } 8.171 \text { que criou o CNPA, } \\
\text { não lhe dando poderes para definir a política } \\
\text { agrícola no País, que permaneceu com o governo } \\
\text { nos gabinetes e nos diversos órgãos dos } \\
\text { ministérios. }\end{array}$ \\
\hline $\begin{array}{l}1995 \text { - Desativação das Câmaras } \\
\text { Setoriais }\end{array}$ & $\begin{array}{l}\text { Desativação das Câmaras Setoriais criadas no } \\
\text { Ministério da Agricultura, principalmente, em } \\
\text { função da ausência do CNPA. }\end{array}$ \\
\hline 2003 - Recriação do CNPA & $\begin{array}{l}\text { Ministério da Agricultura recria o CNPA, através } \\
\text { do Ministro Roberto Rodrigues. }\end{array}$ \\
\hline $\begin{array}{l}2003 \text { - Instalação da Câmara } \\
\text { Setorial da Cadeia Produtiva do } \\
\text { Açúcar e do Álcool }\end{array}$ & $\begin{array}{l}\text { Instalação da Câmara Setorial da Cadeia } \\
\text { Produtiva do Açúcar e do Álcool em } 26 \text { de maio } \\
\text { de 2003, em Brasília. }\end{array}$ \\
\hline $\begin{array}{l}\text { 2004 - Criação da Câmara Setorial } \\
\text { da Cadeia Produtiva do Açúcar e } \\
\text { do Álcool }\end{array}$ & $\begin{array}{l}\text { Criação da Câmara pela Portaria nº154, de } 2 \text { de } \\
\text { julho de } 2004 .\end{array}$ \\
\hline
\end{tabular}

Fonte: Adaptado de STADUTO et al. (2007).

A Câmara Setorial do Açúcar e do Álcool foi criada pelo Mapa, em maio de 2003, como mostra o Quadro 2. É constituída por 47 representantes de 36 entidades, das quais 20 são representantes patronais, 14, governamentais e 2, representantes da classe trabalhadora. Tais componentes são representantes dos diversos segmentos dos setores público e privado, que mantêm interfaces operacionais, ou compõem a cadeia produtiva do Açúcar e do Álcool (por exemplo: Unica, BM\&FBovespa, União Nordestina dos Produtores de Cana, Sindicato da Indústria do Açúcar e Álcool do Estado de Alagoas, etc.). As decisões são tomadas por maioria de votos, sendo cada componente com direito a um voto. Não tem direito a voto os convidados e consultores especiais (de acordo com o Art. $22^{\circ}$ da Portaria no 530, de 12/06/2008, do Mapa).

Desde a criação, a Câmara realizou 11 reuniões. O Quadro 2 traz o resumo do conteúdo das atas e sua relação com a NEI, principalmente no que tange a reivindicações de alterações nos ambientes institucional, tecnológico e organizacional. 
- Um estudo das deliberações da Câmara Setorial do Açúcar e do Álcool, usando análise de correspondência

Quadro 2. Resumo do Conteúdo das Atas e a Relação com a NEI

\begin{tabular}{|c|c|c|}
\hline $\begin{array}{c}\text { Reunião } \\
\text { Ordinária }\end{array}$ & Discussões / deliberações & $\begin{array}{c}\text { Relação } \\
\text { com a NEI }\end{array}$ \\
\hline $\begin{array}{l}\text { 1a Reunião: } \\
\text { 26/06/2003 }\end{array}$ & $\begin{array}{l}\text { - Programa de Estocagem de álcool etílico, discussão } \\
\text { sobre a legislação da Cide (Contribuição sobre } \\
\text { Intervenção no Domínio Econômico). }\end{array}$ & $\begin{array}{l}\text { Ambiente } \\
\text { institucional }\end{array}$ \\
\hline $\begin{array}{l}\text { 2a Reunião: } \\
\text { 26/08/2003 }\end{array}$ & $\begin{array}{l}\text { - Necessidade de redução da carga tributária sobre o } \\
\text { álcool e sobre as distribuidoras; } \\
\text { - Reduzir a tributação diferenciada do ICMS; } \\
\text { - Adoção de um Consecana Nordeste; } \\
\text { - Busca de desenvolvimento de uma Bolsa Internacional } \\
\text { para a comercialização do álcool carburante; } \\
\text { - Importância da existência de um marco regulatório } \\
\text { do setor de álcool combustível. }\end{array}$ & $\begin{array}{l}\text { Ambiente } \\
\text { Institucional } \\
\text { Ambiente } \\
\text { Organizacional }\end{array}$ \\
\hline $\begin{array}{l}\text { 3a Reunião: } \\
\text { 14/10/2003 }\end{array}$ & $\begin{array}{l}\text { - Intenção de parceria Brasil x Cuba para a produção } \\
\text { de álcool naquele país; } \\
\text { - Foco na redução de impostos sobre o álcool, na } \\
\text { redução da sonegação e que o ICMS seja o mesmo em } \\
\text { todos os estados. }\end{array}$ & $\begin{array}{c}\text { Ambiente } \\
\text { Institucional }\end{array}$ \\
\hline $\begin{array}{l}\text { 4a Reunião: } \\
\text { 09/12/2003 }\end{array}$ & $\begin{array}{l}\text { - Estabelecer um marco regulatório consistente para o } \\
\text { setor sucroalcooleiro; } \\
\text { - Decisão de criação de Consecanas em cada estado; } \\
\text { - Assinatura de Convênio BBConvir (financiamentos); } \\
\text { - Reduzir a tributação do ICMS sobre o álcool e reduzir } \\
\text { a tributação de PIS/Cofins (Programa de Integração } \\
\text { Social/Contribuição para o Financiamento da } \\
\text { Seguridade Social); } \\
\text { - Verificação de que o gás GNV sofre tributação menor } \\
\text { que do álcool e da gasolina; } \\
\text { - Detecção de que veículos a álcool que têm IPI } \\
\text { (Imposto sobre Produtos Industrializados) menor } \\
\text { foram convertidos a GNV e isso é uma fraude fiscal; } \\
\text { discutidas barreiras ao açúcar; } \\
\text { - O açúcar é o único produto da cesta básica com 5\% } \\
\text { de IPI, a demanda da Câmara é que esse imposto seja } \\
\text { de 0\%. }\end{array}$ & $\begin{array}{l}\text { Ambiente } \\
\text { Institucional } \\
\text { Ambiente } \\
\text { Organizacional }\end{array}$ \\
\hline \begin{tabular}{|l|} 
5a Reunião: \\
12/02/2004
\end{tabular} & $\begin{array}{l}\text { - Pólo Nacional de Biocombustíveis; } \\
\text { - Apresentação de estudo que mostrou a dimensão que } \\
\text { o álcool combustível ocupará na matriz energética num } \\
\text { horizonte de tempo de, aproximadamente, } 10 \text { anos; } \\
\text { - A entrada do gás na matriz energética é irreversível e } \\
\text { que é fundamental para o setor que haja mudanças } \\
\text { institucionais que corrijam as distorções atuais que } \\
\text { beneficiam a competitividade do gás para fim } \\
\text { combustível veicular; }\end{array}$ & $\begin{array}{l}\text { Ambiente } \\
\text { Organizacional } \\
\text { Ambiente } \\
\text { Institucional }\end{array}$ \\
\hline
\end{tabular}


Quadro 2. Continuação.

\begin{tabular}{|c|c|c|}
\hline $\begin{array}{l}\text { Reunião } \\
\text { Ordinária }\end{array}$ & Discussões / deliberações & $\begin{array}{l}\text { Relação } \\
\text { com a NEI }\end{array}$ \\
\hline $\begin{array}{l}\text { 5a Reunião: } \\
\text { 12/02/2004 }\end{array}$ & $\begin{array}{l}\text { - A situação atual do setor justifica que se peça um } \\
\text { aumento no percentual de mistura de álcool na } \\
\text { gasolina que hoje é de } 25 \% \text {; } \\
\text { - O setor é o responsável por empregar o maior } \\
\text { número de analfabetos ou semianalfabetos do País, } \\
\text { com a mecanização, a preocupação existente é a de } \\
\text { como qualificar o trabalhador e como fazer com que } \\
\text { aqueles que perderem postos de trabalho tenham } \\
\text { condição de arranjar outra ocupação. }\end{array}$ & $\begin{array}{c}\text { Ambiente } \\
\text { Organizacional } \\
\text { Ambiente } \\
\text { Institucional }\end{array}$ \\
\hline $\begin{array}{l}\text { 6a Re } \\
22 / 04\end{array}$ & $\begin{array}{l}\text { - Discussão sobre o relatório da OMS que trata sobre } \\
\text { obesidade e o consumo de açúcar; } \\
\text { - Discussão sobre o Programa de Incentivo às Fontes } \\
\text { Alternativas de Energia Elétrica (Proinfa); } \\
\text { - Discussão sobre o volume de recursos para o } \\
\text { Programa de estocagem de álcool combustível, } \\
\text { provenientes da Cide e a tramitação burocrática junto } \\
\text { aos representantes dos ministérios que compõem o } \\
\text { Conselho Interministerial do Açúcar e do Álcool } \\
\text { (Cima) para que flua com rapidez; } \\
\text { - Mecanismos de controle e rastreabilidade em toda a } \\
\text { cadeia produtiva; } \\
\text { - Ênfase no assunto formação de estoques; } \\
\text { - Relato sobre as reuniões regionais de divulgação do } \\
\text { BBConvir; } \\
\text { - Relato sobre a elaboração de uma minuta de documento } \\
\text { a ser encaminhado ao INSS (Instituto Nacional do Seguro } \\
\text { Social) e a Secretaria da Receita Federal com sugestões de } \\
\text { redução de carga tributária do setor e que essa minuta } \\
\text { precisava da ratificação do Grupo; } \\
\text { - Discussão sobre redução das alíquotas a zero. }\end{array}$ & $\begin{array}{c}\text { Ambiente } \\
\text { Organizacional } \\
\text { Ambiente } \\
\text { Institucional }\end{array}$ \\
\hline $\begin{array}{l}\text { 7a Reunião } \\
\text { 14/07/2004 }\end{array}$ & $\begin{array}{l}\text { - Relato do Ministro da Agricultura, Pecuária e } \\
\text { Abastecimento sobre o anúncio da UE em relação à } \\
\text { redução de subsídios para a produção de açúcar; } \\
\text { - Destaque sobre o Proinfa, o setor não deveria perder } \\
\text { a oportunidade de aumentar a participação da } \\
\text { co-geração na matriz energética nacional; } \\
\text { - Relato sobre o grande interesse do Japão e o grande } \\
\text { volume de investimentos que deveriam ser feitos pelo } \\
\text { JBIC no Pólo Nacional de Biocombustíveis; } \\
\text { - Necessidade de pensar em questões estruturais e de } \\
\text { longo prazo para o setor; } \\
\text { - Necessidade de redução da tributação do álcool hidratado; } \\
\text { - Acelerar as medidas de redução de tributação do } \\
\text { álcool em função da expansão dos veículos flex fuel; }\end{array}$ & $\begin{array}{c}\text { Ambiente } \\
\text { Institucional } \\
\text { Ambiente } \\
\text { Organizacional } \\
\text { Ambiente } \\
\text { Tecnológico }\end{array}$ \\
\hline
\end{tabular}


- Um estudo das deliberações da Câmara Setorial do Açúcar e do Álcool, usando análise de correspondência

Quadro 2. Continuação.

\begin{tabular}{|c|c|c|}
\hline $\begin{array}{l}\text { Reunião } \\
\text { Ordinária }\end{array}$ & Discussões / deliberações & $\begin{array}{l}\text { Relação } \\
\text { com a NEI }\end{array}$ \\
\hline $\begin{array}{l}\text { 7a Reunião: } \\
\text { 14/07/2004 }\end{array}$ & $\begin{array}{l}\text { - Zerar a incidência de PIS e Cofins no álcool } \\
\text { hidratado; } \\
\text { - Pedido ao Ministro que agende uma reunião com o } \\
\text { Ministro da Fazenda com a participação do Sindicom, } \\
\text { de representantes dos revendedores de combustíveis, } \\
\text { Petrobrás, produtores de álcool, parlamentares para que } \\
\text { possam convencer o Ministro da Fazenda a abrir mão } \\
\text { da arrecadação decorrente da publicação do Decreto; } \\
\text { - É fundamental que o setor se organize para estabelecer } \\
\text { um esquema bem organizado de estocagem; } \\
\text { - Relato sobre a parceria entre Brasil e China para } \\
\text { auxiliar a China a inserir o álcool combustível na sua } \\
\text { matriz energética; } \\
\text { - Relato sobre a assembléia de Criação do novo modelo } \\
\text { do Centro de Tecnologia Copersucar (CTC); } \\
\text { - Importante que o setor desenvolva um sistema de } \\
\text { rastreabilidade para açúcar e álcool; } \\
\text { - Sugestão de que o CTC e o Departamento de Defesa } \\
\text { e Inspeção Vegetal do Ministério da Agricultura, } \\
\text { Pecuária e Abastecimento elaborassem proposta de } \\
\text { criação de um modelo de rastreabilidade para o setor. }\end{array}$ & $\begin{array}{c}\text { Ambiente } \\
\text { Institucional } \\
\text { Ambiente } \\
\text { Organizacional } \\
\text { Ambiente } \\
\text { Tecnológico }\end{array}$ \\
\hline $\begin{array}{l}\text { 8a Reunião: } \\
\text { 25/11/2004 }\end{array}$ & $\begin{array}{l}\text { - Preocupação com as barreiras que serão encontradas no } \\
\text { mercado internacional e será fundamental maior } \\
\text { participação do setor no novo CTC (Centro de Tecnologia } \\
\text { Canavieira) que até então não recebeu tantas adesões; } \\
\text { - Sistema tributário incidente sobre o álcool continua } \\
\text { acarretando sérios problemas na comercialização do } \\
\text { produto; } \\
\text { - Os dois problemas mais críticos são a não emissão de } \\
\text { Decreto regulando a Lei no } 10.833 \text {, com a adoção de } \\
\text { alíquota zero de PIS/Cofins incidente nas } \\
\text { distribuidoras e a diversidade de alíquotas de ICMS } \\
\text { que varia de acordo com cada estado da Federação; } \\
\text { - Para que o decreto seja emitido, serão necessárias } \\
\text { forças políticas (relato do coordenador do grupo); } \\
\text { - Relato sobre o mercado de álcool no Brasil que carece } \\
\text { de um instrumento de formação de estoques de } \\
\text { passagem e reguladores. }\end{array}$ & $\begin{array}{l}\text { Ambiente } \\
\text { Tecnológico } \\
\text { Ambiente } \\
\text { Institucional }\end{array}$ \\
\hline $\begin{array}{l}\text { 9a Reunião: } \\
\text { 14/06/2005 }\end{array}$ & $\begin{array}{l}\text { - Apresentação sobre a questão do PIS/Cofins, sendo } \\
\text { exposta também a Lei no } 10.833 \text {, que ainda não foi } \\
\text { regulamentada mesmo após } 12 \text { meses de sua aprovação; } \\
\text { - Discussão sobre o problema de estocagem de álcool. }\end{array}$ & $\begin{array}{c}\text { Ambiente } \\
\text { Institucional } \\
\text { externo } \\
\text { Ambiente } \\
\text { Institucional }\end{array}$ \\
\hline
\end{tabular}


Quadro 2. Continuação.

\begin{tabular}{|l|l|c|}
\hline \multicolumn{1}{|c|}{$\begin{array}{c}\text { Reunião } \\
\text { Ordinária }\end{array}$} & \multicolumn{1}{|c|}{ Discussões / deliberações } & $\begin{array}{c}\text { Relação } \\
\text { com a NEI }\end{array}$ \\
\hline $\begin{array}{l}\text { 10a } \\
\text { Reunião: } \\
10 / 08 / 2005\end{array}$ & $\begin{array}{l}\text { - Alerta os problemas decorrentes da utilização de álcool } \\
\text { carburante fora das especificações técnicas da ANP; } \\
\text { - Discussão sobre os parâmetros do modelo Consecana } \\
\text { e em seguida o Ministro disse que o governo não } \\
\text { aceita que o setor continue a apresentar distorções } \\
\text { quanto à remuneração dos agentes envolvidos. }\end{array}$ & $\begin{array}{c}\text { Ambiente } \\
\text { Organizacional }\end{array}$ \\
\hline $\begin{array}{l}\text { - O Ministro apontou que para o crescimento equilibrado } \\
\text { do setor é necessária visão de longo prazo, estocagem de } \\
\text { Reunião: } \\
\text { 23/01/2006 }\end{array}$ & $\begin{array}{l}\text { álcool e que se trate da tributação do álcool; } \\
\text { - O representante da Abicab pediu que o governo } \\
\text { regulasse o mercado de forma a não permitir } \\
\text { - Exposição sobre um Plano Setorial de Qualificação, } \\
\text { que pretende beneficiar uma série de trabalhadores ao } \\
\text { longo da cadeia produtiva, tanto do campo como da } \\
\text { indústria e da administração das usinas. }\end{array}$ & $\begin{array}{c}\text { Ambiente } \\
\text { Institucional } \\
\text { Ambiente } \\
\text { Organizacional }\end{array}$ \\
\hline
\end{tabular}

Fonte: Mapa (2007).

\section{A Nova Economia Institucional (NEI)}

A Nova Economia Institucional (NEI) surgiu inicialmente com Ronald Coase, em 1937, como uma nova teoria da firma. De acordo com Williamson (1996), essa teoria trabalha com duas vertentes de análise, a macro associada principalmente ao trabalho de North (1994), que trata do desenvolvimento das instituições, e a micro, que trata das instituições de governança.

Em 1937, o artigo de Coase, intitulado The Nature of the Firm, contribuiu sobremaneira para o desenvolvimento da NEI e se tornou um marco para essa teoria. Neste artigo, de acordo com Farina et al. (1997), Coase investigou o motivo que leva à existência de firmas e até que ponto elas crescem, ou seja, focou seu estudo em duas formas de coordenação: mercado e firma, buscando entender quais os limites da firma, até onde ocorre a integração vertical e a partir de quando essa é interrompida e passa-se ao mercado.

Para Coase (1993), a firma deixa de ser representada apenas como uma função de produção e passa, também, a ser considerada um complexo de contratos a jusante e a montante. A opção entre mercado e hierarquia (firma) se faz com base nos custos de se recorrer a um ou a outro, os chamados custos de transação. O limite da firma é o ponto onde o custo de internalizar uma transação é maior do que o custo de realizá-la via 
- Um estudo das deliberações da Câmara Setorial do Açúcar

e do Álcool, usando análise de correspondência

mercado. $\mathrm{O}$ mercado oferece incentivos à produção enquanto que a hierarquia oferece maior controle do empresário. Assim, a escolha entre mercado e hierarquia depende dos custos de transação.

Williamson (1989) define os custos de transação como os custos de administração do sistema econômico e são relativos às fricções no sistema. Para Williamson, a economia tradicional analisa o sistema econômico como se não houvesse atrito, ou seja, sem considerar os custos de transação. Coase (1993) define os custos de transação como o custo dos agentes se encontrarem no mercado para transacionar, o custo de elaborar os contratos e o custo de monitoramento dos contratos.

Cheung (1990), apud Farina et al. (1997), complementam a análise de Coase com respeito aos custos de transação e definem como sendo os custos de elaboração e negociação dos contratos, mensuração e fiscalização de direitos de propriedade, monitoramento do desempenho e organização de atividades. Apesar disso, esta análise ainda desconsidera um dos principais fatores que influenciam a eficiência econômica, que é a capacidade de adaptação a mudanças.

A vertente macro da NEI analisa de que forma as instituições podem influenciar a eficiência econômica, diminuindo a assimetria de informações entre os agentes, reduzindo a incerteza e garantindo os direitos de propriedade. Porém, a médio e longo prazos, os agentes econômicos também podem influenciar as instituições, na tentativa de adequá-las aos interesses do setor a que pertencem.

Para efeito de uma discussão mais atual da NEI, Gala (2003) analisa especificamente a retórica de Douglass North, dizendo que o mesmo, ao identificar dificuldades da teoria neoclássica no trato de certos problemas econômicos, reexaminou-os com proficiência, destacando que as instituições é que vão determinar as oportunidades em uma sociedade. Evans (2003), com mais cautela, aprimora esta concepção, dizendo nem toda mudança institucional vai criar per se uma oportunidade benéfica para a sociedade. Uma condição para que isto ocorra é o fato de a mudança institucional estar alicerçada na tomada de decisões locais, não sendo simplesmente "importada".

Respeitando a peculiaridade das condições e dos problemas locais, Azevedo (2000) mostra como a NEI pode ser usada como referencial geral e aplicações para a agricultura brasileira [destacando as regras formais (políticas agrícolas e regulamentação), as regras informais (códigos de ética, costumes) e os direitos de propriedade da terra]. Shikida et al. 
(2007), em análise da mudança organizacional da agroindústria canavieira paranaense pós-desregulamentação setorial, colocam a importância de se entender os ambientes vigentes neste setor específico para compreender como de fato ocorre o processo relacionado ao avanço da competitividade das empresas.

\subsection{Ambientes Institucional, Tecnológico e Organizacional}

"As instituições compreendem regras formais, limitações informais e os mecanismos responsáveis pela eficácia desses dois tipos de normas" (NORTH, 1994, p. 13). Neste sentido, as instituições representam as regras do jogo e, em última instância, são essas regras que determinarão que tipo de organizações existirá nesse sistema ou na economia. As instituições, juntamente com a tecnologia adotada, irão afetar os custos das organizações, tanto os custos de produção como os de transação.

As organizações "compõem-se de grupos de indivíduos dedicados a alguma atividade executada com determinado fim" (NORTH, 1994, p. 13). Ou seja, podem ser empresas que visam o lucro, uma escola que visa a formação de alunos, um time de futebol que visa a vitória, etc., e, como as instituições são chamadas de regras do jogo, as organizações seriam os jogadores.

As mudanças institucionais, de acordo com North (1994), se dão através dos seguintes elementos: agentes, fontes, processo e direcionamento. Os agentes de mudança são aqueles que detêm o poder de decisão nas organizações; as fontes de mudança são percebidas pelos agentes e surgem de alguma novidade inserida no meio - não significa que sejam positivas, podem ter efeito positivo ou negativo. O processo de mudança institucional é lento, visto que mudanças de regras não são rápidas; regras formais precisam ser absorvidas e o processo é lento, pois sempre existem aqueles atores que não querem a mudança. E quando isso ocorre, é necessário que haja negociação entre as partes envolvidas, uma certa barganha. A direção da mudança, de acordo com North (1994), depende do curso adotado e do interesse das organizações.

Para Farina (1999), são as falhas de mercado que abrem espaço para as políticas públicas, e o Estado, pelo seu papel de definidor das "regras do jogo", influencia a competitividade entre as organizações, pois depende do Estado a definição de direitos de propriedade, regras para contratos, etc.

Neste contexto, os padrões de concorrência podem se alterar ao longo do tempo, devido às mudanças nas instituições (abertura comercial), no 
- Um estudo das deliberações da Câmara Setorial do Açúcar

e do Álcool, usando análise de correspondência

ambiente tecnológico (biotecnologia) e no ambiente organizacional (formação de redes horizontais e Câmaras Setoriais) (FARINA, 1999).

A Figura 1 mostra que o ambiente competitivo, no qual atuam as organizações, influencia diretamente as estratégias individuais e, consequentemente, o desempenho e sobrevivência destas instituições. Porém, este ambiente competitivo é influenciado pelos ambientes tecnológico (paradigmas tecnológicos), institucional (sistema legal, regulamentação e políticas) e o ambiente organizacional formado pelas organizações corporatistas e demais associações e políticas setoriais privadas.

Figura 1. Competitividade e Coordenação de Sistemas Agroindustriais

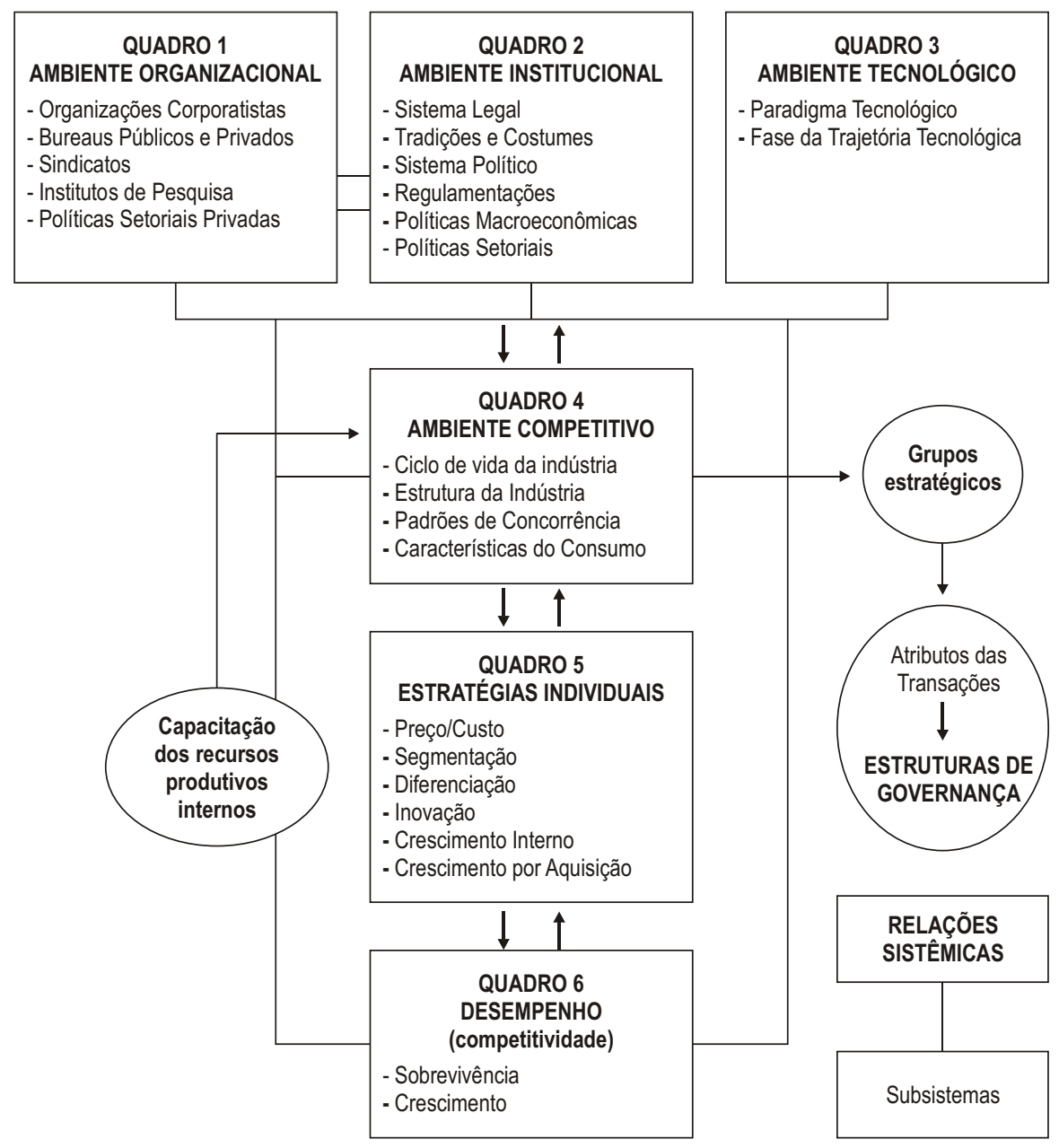

Fonte: Farina (1999). 
A relação citada, contudo, ocorre no curto prazo. No longo prazo, o processo inverso pode acontecer, ou seja, as estratégias individuais podem afetar o ambiente competitivo e, consequentemente, os ambientes organizacional, institucional e tecnológico.

Diante do exposto, é possível verificar, a luz da NEI, que as Câmaras Setoriais surgiram de uma readequação organizacional e buscam adaptar, mesmo que no longo prazo, os ambientes institucional, tecnológico e competitivo, no intuito de alcançar um melhor desempenho nos sistemas produtivos a que pertencem. No entanto, ao mesmo tempo em que influenciam, são influenciadas pelos atuais ambientes organizacional, tecnológico e institucional.

Para Staduto et al. (2007), as Câmaras Setoriais, devido ao seu caráter tripartite, são mecanismos redutores de assimetria de informação entre o Estado, os trabalhadores e os empresários e servem para legitimar as ações do Estado junto aos setores participantes.

Como as Câmaras Setoriais são fóruns de discussão no qual se encontram entidades patronais, governamentais e representantes dos trabalhadores, o Estado tem a oportunidade de ouvir os trabalhadores e empresários e afinar suas ações com as reais necessidades do setor.

Segundo Marschall et al. (2005), as Câmaras Setoriais diminuem a racionalidade limitada do Estado, tornando as ações mais eficazes por parte do governo, que converte legítima suas políticas, e por parte do setor privado, que almeja um ambiente institucional cada vez mais favorável às suas atividades.

\section{Aspectos Metodológicos}

Depois de levantados os elementos teóricos necessários para fundamentação do presente trabalho, faz-se necessário uma abordagem da metodologia estatística multivariada que será utilizada para a análise das atas referentes à Câmara Setorial do Açúcar e do Álcool.

Segundo Reis (1997), pode-se afirmar que a análise multivariada é um conjunto de métodos estatísticos que permite analisar simultaneamente medidas múltiplas para cada indivíduo ou objeto, isto é, qualquer método de análise que permita considerar duas ou mais variáveis pode ser considerado pertencente a esse campo científico.

A estatística multivariada permite analisar a relação entre múltiplas variáveis independentes e/ou múltiplas variáveis dependentes, quer estabeleçam ou não uma relação causa/efeito entre elas. 
- Um estudo das deliberações da Câmara Setorial do Açúcar

e do Álcool, usando análise de correspondência

Para Pereira (2001), existem dois princípios gerais nas técnicas de análise multivariada que auxiliam o pesquisador a desenvolver suas pesquisas: proximidade geométrica e redução de dimensionalidade. As principais técnicas de análise multivariada são: análise de cluster; escalonamento multidimensional; análise fatorial; e análise de correspondência. No presente artigo utilizar-se-á a técnica de análise de correspondência.

A análise de correspondência é uma técnica multivariada utilizada para examinar variáveis categóricas, por meio de seu cruzamento ou contingenciamento, tomando-se como base a distribuição de massa do conjunto de observações (PEREIRA, 2001).

Em análise de correspondência, chamam-se massa as freqüências marginais de uma tabela de contingência e elas são interpretadas como pesos para um perfil de distribuição de freqüências pelas categorias consideradas. Pode-se focalizar a distribuição de massa de linha (Row profile) ou de colunas (Column Profile), ou ambas simultaneamente.

Neste sentido, para Pereira (2001), os pesos são atribuídos por linhas ou por colunas. Isso caracteriza um perfil na distribuição dos dados. O peso é o resultado da divisão das distribuições por linha (coluna) pelo total acumulado pela linha (coluna). A média dos perfis recebe o nome de centróide, e representa as freqüências marginais relativas. $O$ centróide pode ser considerado o ponto de equilíbrio da distribuição de massa das observações -é um centro gravitacional com os dados distribuídos em sua órbita.

O centróide, como é a média dos perfis, é também o valor esperado para cada perfil. Com isso, pode-se constatar que as distâncias entre os pontos e o centróide são distâncias entre valores observados e esperados, e são chamadas de distâncias qui-quadrado, que é uma distância semelhante à distância euclidiana, porém, com a ponderação da massa como fator de atração ou repulsão.

Outra medida importante na análise de correspondência é a inércia, que é a média das distâncias qui-quadrado de todos os objetos em relação ao centróide. A inércia será zero quando todos os pontos estiverem sobre o centróide, e terá o valor máximo possível igual ao número de dimensões originais menos 1 . Por exemplo, em um sistema tridimensional, o valor máximo da inércia é 2 . A raiz quadrada da inércia é chamado de eigenvalue, que é o valor singular em análise de correspondência. É uma razão de variâncias entre escores de linhas e colunas que sugere quanto das variações totais está sendo coberta pela dimensão. 
Para Pereira (2001), a razão entre o valor singular de uma dimensão e a soma dos valores singulares de todas as dimensões mostra se existe um bom ajustamento dos dados - normalmente, é considerado no modelo as dimensões com valores singulares superiores a 0,2 .

Após as análises da inércia e do eingevalue, os dados podem ser dispostos em um gráfico, com os escores dos objetos para localização no sistema plano normalizado, ou seja, é dada uma padronização nos valores com unidades abstratas de medida. Essa normalização é feita por linha, por coluna, ou por ambas. O método mais usado é utilização de ambas (linhas e colunas), chamada de normalização canônica. A análise do gráfico normalmente é feita considerando as relações de proximidade geométrica entre os pontos e os centróides, mostrando como cada observação está mais próxima de uma determinada média nas dimensões.

A análise de correspondência será utilizada para analisar as atas da Câmara Setorial em estudo, a partir da construção da tabela disjuntiva completa (Tabela 1), no qual as linhas serão formadas pelo resumo das atas das reuniões $(n=11)$ e as colunas serão compostas pelos três ambientes macro-analíticos da NEI: ambiente institucional; ambiente organizacional; e ambiente tecnológico. Tem-se, então, uma variável codificada que assume valor 1 se a reunião abordou o tema referente ao ambiente em análise e 0 se não.

Tabela 1. Tabela de Contingência Disjuntiva completa referente aos ambientes macro-analíticos da NEI

\begin{tabular}{lcccc}
\hline & $\begin{array}{c}\text { Amb. } \\
\text { Institucional }\end{array}$ & $\begin{array}{c}\text { Amb. } \\
\text { Organizacional }\end{array}$ & $\begin{array}{c}\text { Amb. } \\
\text { Tecnológico }\end{array}$ & TOTAL \\
\hline Reunião 1 & 1 & 0 & 0 & 1 \\
Reunião 2 & 1 & 1 & 0 & 2 \\
Reunião 3 & 1 & 0 & 0 & 1 \\
Reunião 4 & 1 & 1 & 0 & 2 \\
Reunião 5 & 1 & 1 & 0 & 2 \\
Reunião 6 & 1 & 1 & 0 & 2 \\
Reunião 7 & 1 & 1 & 1 & 3 \\
Reunião 8 & 1 & 0 & 1 & 2 \\
Reunião 9 & 1 & 0 & 0 & 1 \\
Reunião 10 & 0 & 1 & 0 & 2 \\
Reunião 11 & 1 & 1 & 0 & 19 \\
\hline TOTAL & 10 & 7 & 2 & \\
\hline
\end{tabular}

Fonte: Mapa (2007). 
A análise de componentes principais permitirá avaliar quais as principais reivindicações dos componentes da Câmara no que tange a alterações nos ambientes em análise e quais reuniões se relacionam mais com quais ambientes.

\section{Resultados e discussões}

A Tabela 2 mostra o resultado da análise de correspondência. Pode-se constatar que a primeira dimensão extrai a maioria das informações, pois possui o autovalor mais elevado. A análise realizada sobre as atas das reuniões e os três ambientes mostra que a primeira dimensão extrai $62,24 \%$ da inércia total e a segunda dimensão aumenta a inércia explicada em $37,75 \%$, ou seja, as duas dimensões explicam juntas 100\% da inércia.

Tabela 2. Autovalores e Inércia para as dimensões

\begin{tabular}{llllll}
\hline Dimensões & Valores sing & Autovalor & \% inércia & \% acum. & Qui-quadra \\
\hline 1 & 0,609928 & 0,372012 & 62,24897 & 62,24897 & 7,068222 \\
2 & 0,474981 & 0,225607 & 37,75103 & 100,00 & 4,286539 \\
\hline Total inércia: & 0,59762 & $\mathrm{Chi}^{2}: 11,355$ & df: 20 & pvalor: 0,93646 \\
\hline
\end{tabular}

Fonte: Resultados da pesquisa.

Em um espaço plano, numa representação gráfica, pode-se examinar os resultados da análise de correspondência. A análise gráfica faz-se pelo exame das relações de proximidade geométrica dos objetos (reuniões) com os caracteres (ambientes). Dessa forma, pode se dizer, de forma generalizada, que o mapa reflete as intenções dos agentes (membros da Câmara) quando da realização das reuniões.

O mapa de análise de correspondência foi elaborado a partir de uma matriz binária 11x3, obtida por meio dos valores da Tabela 1 de contingência disjuntiva completa. Assim, a disposição dos dados no mapa pode ser interpretada pelos valores referentes aos ambientes, em que cada ponto cria um campo de influência. 
Figura 2. Mapa da Análise de Correspondência

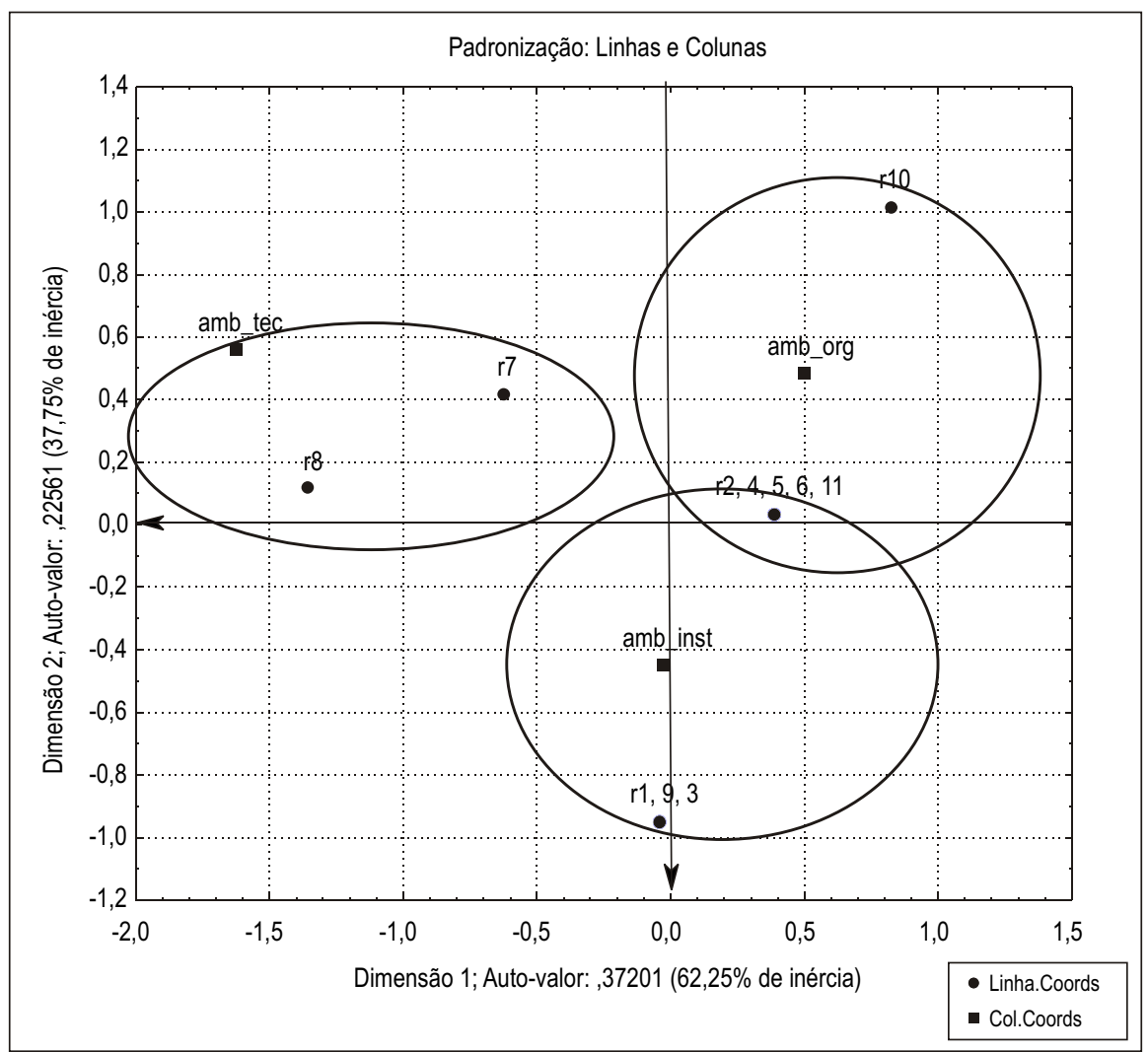

Fonte: Resultados da Pesquisa.

A análise se dá em duas dimensões, que é o máximo de dimensões que se pode ter com três categorias inicialmente consideradas. Com isso, pode-se julgar que o modelo de análise de correspondência representará perfeitamente o ajuste dos dados.

A primeira dimensão separa as reuniões 7,8 e o ambiente tecnológico no lado esquerdo e as reuniões $2,4,5,6,11$ e 10 e o ambiente organizacional no lado direito. $\mathrm{O}$ ambiente institucional e as reuniões 1,9 e 3 ficam praticamente sobre o ponto $(0,0)$, centróide da dimensão 1 .

Diante dos resultados apresentados pelo mapa de análise de correspondência (que mostra a relação entre os ambientes e as reuniões) e tendo como parâmetro o resumo do conteúdo das Atas e a relação com a NEI exposta no Quadro 2, constata-se que as reuniões 7 e 8 se aproximam mais do ambiente tecnológico [dentre essas discussões pode-se destacar a 
criação do novo modelo do Centro de Tecnologia Copersucar (CTC)], ou seja, nessas reuniões, os assuntos tratados estiveram mais relacionados com demandas referentes a esse ambiente.

As reuniões 1, 3 e 9 aproximam-se mais do ambiente institucional (focaram suas discussões nos assuntos relacionados ao ambiente institucional, como questões voltadas para a legislação da Cide, alterações no ICMS e mudanças na legislação PIS/Cofins), enquanto a reunião 10 aproxima-se mais do ambiente organizacional [teve seus assuntos voltados ao ambiente organizacional, como a criação de conselhos regionais (Consecana), cujo objetivo maior é reduzir as distorções regionais do setor].

As reuniões 2, 4, 5, 6 e 11 aproximam-se tanto do ambiente organizacional quanto do ambiente institucional, o que caracteriza que, nestas reuniões, os assuntos tratados permeavam demandas referentes aos dois ambientes (foram discutidos temas como os Consecanas, Bolsa Internacional para comercialização de álcool, convênio com o Banco do Brasil para financiamentos, alteração no IPI e outros).

Verifica-se que as questões tributárias, ligadas ao ambiente institucional, foram as que mais se destacaram. Neste caso, em estudo sobre as cooperativas da agroindústria canavieira do Paraná, Marschall et al. (2004) salientam que por influir positivamente no desempenho das cooperativas canavieiras paranaenses, percebe-se que a legislação tributária cresce em importância conquanto o setor busca negociar a redução de impostos, sobretudo do PIS/Cofins. E isto se repete para as usinas de modo geral.

Vale frisar que, com o processo de desregulamentação da agroindústria canavieira nacional (citado na seção 2 deste artigo) - em que "o papel do Estado mudou, ele agora é mais de coordenador do que interventor" (VIAN, 2003, p.11) -, várias mudanças ocorreram neste setor da economia. Para Moraes (2000), em função da desregulamentação setorial, muitos desafios estão sendo enfrentados pela agroindústria canavieira em decorrência da necessidade de um eficaz planejamento da oferta de cana-de-açúcar, visando atender tanto ao mercado de açúcar como de álcool, seja no âmbito nacional ou internacional.

Desta forma, confirma-se, a guisa da Nova Economia Institucional e do mapa de análise de correspondência, que a Câmara Setorial procura uma readequação organizacional, com o fito de adaptar os ambientes institucional, tecnológico e competitivo, no intuito de alcançar um melhor desempenho no setor sucroalcooleiro. 


\section{Considerações finais}

O presente artigo teve como objetivo analisar as principais deliberações da Câmara Setorial do Açúcar e do Álcool, no sentido de influenciar os ambientes institucional, tecnológico e organizacional no qual está inserida.

O setor sucroalcooleiro é de suma importância para a economia nacional, tanto pelo valor econômico quanto ambiental e social. Por isso, a Câmara tem um papel de grande relevância para o País. Este setor, como todos os outros da economia, influencia e é influenciado pelos ambientes institucional, organizacional e tecnológico, e uma das maneiras de se perceber essa influência é por meio de sua Câmara Setorial.

A Câmara Setorial do Açúcar e do Álcool é um fórum de discussões, no qual estão presentes entidades representativas do Estado, da iniciativa privada e dos trabalhadores. A presença do Estado na Câmara é de grande relevância, visto que diminui a assimetria de informações com o setor privado. Assim, a Câmara Setorial é uma ferramenta de interação do setor privado junto ao Estado para melhor adaptar os ambientes institucional, tecnológico e organizacional às necessidades do setor sucroalcooleiro. Neste ínterim, trabalhadores não tiveram muitas questões para serem discutidas no âmbito desta Câmara, dominadas prioritariamente por representações patronais e pública. Não se pode precisar a razão dessa pouca discussão, porém, vale rememorar que a Câmara Setorial do Açúcar e do Álcool é constituída por 47 representantes de 36 entidades, sendo 20 representantes patronais, 14 governamentais e apenas 2 representantes da classe trabalhadora.

Analisando as onze atas de reuniões desta Câmara Setorial realizadas até o momento, com o auxílio da metodologia estatística de análise multivariada, pode-se concluir que as reivindicações feitas pela Câmara tiveram relação com os três ambientes em estudo.

Analisando-se o mapa de análise de correspondência e o Quadro 2, que sintetiza os assuntos tratados nas atas da Câmara Setorial do Açúcar e do Álcool, pode-se concluir que a maior parte das reuniões da Câmara tratou de assuntos referentes às necessidades voltadas a alterações no ambiente institucional, principalmente no que diz respeito a questões tributárias.

Não obstante, a principal contribuição desses resultados é quanto ao mérito das discussões em cada ambiente macro-analítico, bem como a 
discussão de seus sub-itens como tributação, política econômica, agrícola etc. Destarte, quando se realça com veemência questões com a Cide, ICMS, PIS/Cofins, IPI, INSS, e outros arranjos tributários, o setor está discutindo, dentre outras coisas, aspectos relacionados com o "eterno" embate entre o setor produtivo, visando reduzir impostos, e o setor público, buscando recolher o que pensa ser justo em termos de tributação do setor.

Ademais, este trabalho corrobora a maior preocupação com o ambiente institucional, mormente com questões tributárias, porque, de certa forma, o ambiente tecnológico da agroindústria canavieira já é considerado um padrão de referência mundial, com elevados índices de produtividade de cana, açúcar e álcool (SHIKIDA et al., 2002; PAULILLO et al., 2007). Com isso, a questão relacionada a o ambiente tecnológico perde força relativa vis-à-vis o ambiente institucional supracitado.

Há vários anos a indústria da cana-de-açúcar, instituições de pesquisa, fabricantes de equipamentos e de insumos e consultorias especializadas, vem contribuindo para o desenvolvimento tecnológico nas áreas agrícola e industrial, levando a indústria brasileira a ocupar posição de liderança no cenário internacional. Embora não se disponha de registros precisos sobre os investimentos realizados em pesquisa e desenvolvimento na indústria da cana, estima-se que ao longo dos últimos 30 anos, tenha sido investido perto de um bilhão de dólares, principalmente pelo setor produtivo (SZWARC, 2008, p.1).

E, em termos organizacionais, a preocupação maior das deliberações da Câmara tem sido com o sistema Consecana, que procura divulgar mensalmente valores de referência do preço da tonelada de cana-de-açúcar e da participação do custo de reposição da cana-de-açúcar nos seus produtos finais, estando também ligada indiretamente à questão tributária. De acordo com a Associação de Produtores de Álcool e Açúcar do Estado do Paraná (Alcopar) (2008), o Consecana divulga também os preços projetados da cana básica para todo o ano safra, incluindo os valores no campo com e sem PIS/Cofins, e da cana básica na esteira com e sem PIS/Cofins.

Por último, mas não menos importante, este trabalho procurou analisar as principais ações da Câmara Setorial do Açúcar e do Álcool no sentido de influenciar os ambientes institucional, tecnológico e 
organizacional, valendo-se fundamentalmente dos instrumentais da NEI e da análise de correspondência. Destarte, como futura extensão do presente estudo, sugere-se que mais pesquisas possam ser implementadas para examinar novas contextualizações do setor sucroalcooleiro em níveis que esta proposição metodológica não possibilitou conclusões. Se esta pesquisa suscitar outra(s), a ciência e o setor em epígrafe agradecerão.

\section{Referências Bibliográficas}

ALCOPAR. Associação de Produtores de Álcool e Açúcar do Estado do Paraná. Consecana-PR. Disponível em: <http://www.alcopar.org.br>. Acesso em 17 set. 2008.

ANDERSON, P. Câmaras setoriais: histórico e acordos firmados 1991/95. Rio de Janeiro: IPEA, set. de 1999. (Texto para Discussão, n. 667).

AZEVEDO, P. F. Nova economia institucional: referencial geral e aplicações para a agricultura. Agricultura em São Paulo, v. 47, n.1, p. 33-52, 2000.

BACHA, C. J. C. Economia e política agrícola no Brasil. São Paulo: Atlas. 2004. 226p.

BAER, W. A economia brasileira contemporânea. São Paulo: Nobel. 2002. 509 .

BRASIL. Ministério da Agricultura, Pecuária e Abastecimento (MAPA). Secretaria de Relações Internacionais do Agronegócio. Agronegócio brasileiro: desempenho do comércio exterior. 2 edição. Brasília: MAPA/SRIA/DPIA/CGOE, 2006. 116p.

BRASIL. Ministério da Agricultura, Pecuária e Abastecimento (MAPA). Atas das reuniões da Câmara Setorial da Cadeia Produtiva do Açúcar e do Álcool. Disponível em: <http://www.agricultura.gov.br/portal/ page?_pageid=33,3292734\&. >. Acesso em 27 jun. 2007.

CHEUNG, S. On the new institutional economics. In: CHEUNG, S. et al. Contract economics. Blackwell/Lars Werin and Hans Wijkander, 1990. p. 48-75.

COASE, R. The nature of the firm. In: WILLIAMSON, O.; WINTER, S. G. (Ed.) The nature of the firm origins, evolution, and development. New York: Oxford University Press, 1993. p.18-33 
EVANS, P. Além da "monocultura institucional": instituições, capacidades e o desenvolvimento deliberativo. Sociologias, ano 5, n.9, p.20-63, jan./jun. 2003.

FARINA, E. M. M. Q. Competitividade e coordenação de sistemas agroindustriais: um ensaio conceitual. Gestão \& Produção, São Carlos, v. 6, n. 3, p. 147-161, dez. 1999.

FARINA, E. M. M. Q.; AZEVEDO, P. F.; SAES, M. S. M. Competitividade: mercado, estado e organização. São Paulo: Singular, 1997. 286p.

FIANI, R. A. teoria dos custos de transação. In KUPFER, D.; HASENCLEVER, L. Economia Industrial. Rio de Janeiro: Campus. 2002. p.267-286.

GALA, P. A retórica na economia institucional de Douglass North. Revista de Economia Política, v.23, n. 2 (90), p.123-134, abr./jun. 2003.

GREMAUD, A. P.; VASCONCELlOS, M. A. S.; TONETO JR., R. Economia brasileira contemporânea. São Paulo: Atlas. 2002. 626 p.

MARSCHALL, C. R.; RISSARDI JÚNIOR, D. J.; LIMA, D. P. de; SHIKIDA, P. F. A. O pensamento diretivo das cooperativas da agroindústria canavieira do Paraná à guisa da Nova Economia Institucional. Revista de Economia e Agronegócio, Viçosa (MG), v.2, n.4, p.473-494, out./dez. 2004.

MARSCHALL, C. R.; RISSARDI JÚNIOR, D. J.; STADUTO, J. A. R.; SHIKIDA, P. F. A. As políticas setoriais na agroindústria canavieira paranaense: um enfoque neocorporativista. Redes, Santa Cruz do Sul, v.10, n.1, p.43-65, jan./abr. 2005.

MORAES, M. A. F. D. de A desregulamentação do setor sucroalcooleiro do Brasil. São Paulo: Americana, 2000. 238p.

NORTH, D. Custos de transação, instituições e desempenho econômico. Rio de Janeiro: Instituto Liberal, 1994. 38p.

PAUlillo, L. F.; MELlO, F. O. T.; VIAN, C. E. F. Análise da competitividade das cadeias de agroenergia no Brasil. In: BUAINAIN, A. M.; BATALHA, M. O. (Coord.). Análise da competitividade das cadeias agroindustriais brasileiras. São Carlos: DEP-UFSCAR/IE-UNICAMP, fev. 2006. 119 p. (Projeto MAPA/IICA). 
PAULILLO, L. F.; VIAN, C. E. de F.; SHIKIDA, P. F. A.; MELLO, F. T. de Álcool combustível e biodiesel no Brasil: quo vadis?. Revista de Economia e Sociologia Rural, Brasília, v.45, n.03. p.531-565, jul./set., 2007.

PEREIRA, J. C. R. Análise de dados qualitativos: estratégias metodológicas para as ciências da saúde, humanas e sociais. São Paulo: Edusp, 2001. 153p.

PONDÉ, J. L. S. P. S. Organização das grandes corporações. In: KUPFER, D.; HASENCLEVER, L. Economia industrial. Rio de Janeiro: Campus. 2002. p. 287-306.

REIS, E. Estatística multivariada aplicada. Lisboa: Silabo, 1997. 343 p.

SCHMIDTKE, C. R.; VIEIRA, D. C.; STADUTO, J. A. R.; ROCHA JR., W. F. Câmaras setoriais do agronegócio brasileiro: uma abordagem voltada à Nova Economia Institucional. In: CONGRESSO DA SOCIEDADE BRASILEIRA DE ECONOMIA E SOCIOLOGIA RURAL, 44, Fortaleza, 2006. Anais. Fortaleza: SOBER, 2006.

SHIKIDA, P. F. A. A evolução diferenciada da agroindústria canavieira no Brasil de 1975 a 1995. Piracicaba, 1997. 185 p. Tese de Doutorado em Economia Aplicada. Escola Superior de Agricultura "Luiz de Queiroz", Universidade de São Paulo.

SHIKIDA, P. F. A.; NEVES, M. F.; REZENDE, R. A. Notas sobre a dinâmica tecnológica e agroindústria canavieira no Brasil. In: MORAES, M. A. F. D. de; SHIKIDA, P. F. A. (Orgs.) Agroindústria canavieira no Brasil: evolução, desenvolvimento e desafios. São Paulo: Atlas, 2002. p.120-138.

SHIKIDA, P. F. A.; VIAN, C. E. de F.; LIMA, R. A. de S.; SILVA, J. R. da; DAHMER, V. de S. Mudança organizacional da agroindústria canavieira paranaense pós-desregulamentação setorial. In: ENCONTRO BRASILEIRO DE ESTUDOS REGIONAIS, 5, Recife, 2007. Anais. Recife: ENABER, 2007.

STADUTO, J. A. R.; ROCHA JÚNIOR, W. F. da; GONÇALVES JÚNIOR, C. A., ALVES, Y. B. As câmaras setoriais do agronegócio brasileiro. In: CONGRESSO DA SOCIEDADE BRASILEIRA DE ECONOMIA E SOCIOLOGIA RURAL, 45, Londrina, 2007. Anais. Londrina: SOBER, 2007. 
SZWARC, A. Ninguém é líder por acaso. Disponível em: $<$ http://www.unica.com.br/opiniao/show.asp? msgCode=48E648D5-62 80-4BFE-9443-CAEC0ADE0169>. Acesso em 10 nov. 2008.

TAKAGI, M. Câmaras setoriais agroindustriais, representações de interesses e políticas públicas. 1 ed. Rio de Janeiro: Annablume, 2004. 146p.

VIAN, C. E. de F. Agroindústria canavieira: estratégias competitivas e modernização. Campinas: Átomo, 2003. 216p.

VILELA, D.; ARAÚJO, P. M. M. (Org.) Contribuições das câmaras setoriais e temáticas à formulação de políticas públicas e privadas para o agronegócio. Brasília : MAPA/SE/CGAC, 2006. 496p.

WILLIAMSON, O. E. Las instituciones económicas del capitalismo. Tradução de Eduardo L. Suárez. 1 Edição. México: Fondo de Cultura Económica S/A, 1989. 435p.

WILLIAMSON, O. E. The mechanisms of governance. New York: Oxford University Press, 1996. 429p.

ZYLBERSZTAJN, D. Papel dos contratos na coordenação agro-industrial: um olhar além dos mercados. Revista de Economia e Sociologia Rural, v.43, n.3, p.385-420. jul./set. 2005. 